\title{
Sonological appearance of idiopathic arterial calcification in fetus: A rare case
}

\author{
BR Nagaraj, Prakash Jain, Deepu Alex Thomas, M Raghu \\ Department of Radio Diagnosis, Bangalore Medical College and Research Institute, Bangalore, India
}

Correspondence: Dr. Raghu M, Room No 39, BMC PG Hostel for Men, Near Royan Circle, 1st Main Road, Chamarajpet, Bangalore - 560 018, India. E-mail: raghu2murthy@gmail.com

\begin{abstract}
Idiopathic arterial calcification (IAC) is a rare disease characterized by extensive arterial wall calcification. This condition is almost always fatal. A total of 162 cases have been reported to date, with most cases diagnosed postnatally and less than 13 cases having been suspected antenatally. This case report describes a case of IAC detected antenatally with USG at 28 weeks' gestation.
\end{abstract}

Key words: Echogenic aorta; fetal hydrops; idiopathic arterial calcification

\section{Introduction}

Idiopathic arterial calcification (IAC) is a rare cause of arterial calcification $^{[1]}$ and results in death in early life. Idiopathic arterial calcification presents with varied clinical symptoms in infancy and childhood. ${ }^{[2]}$ Death is due to refractory hypertension and cardiac failure. ${ }^{[3]}$ A total of 162 cases $^{[4,5]}$ have been reported in the literature, with most cases diagnosed postnatally by autopsy and less than 13 cases $^{[6]}$ detected antenatally.

USG is a sensitive and accepted method for the prenatal detection of IAC. ${ }^{[7]}$

\section{Case Report}

An unbooked, 25-year-old, consanguineously married woman with 7 months' amenorrhea was referred for routine obstetric USG. Her parity index was gravida 3, para 2, living 1 and dead 1 . Her first child was healthy and the second baby had died 1 week after birth; the cause of neonatal death was not known. Her hemoglobin was 9 gm/100 ml; she was $\mathrm{Rh}$ positive. The TORCH test was negative. Maternal serum calcium, phosphorus and alkaline phosphatase levels were within normal limits.

Antenatal USG (Logiq 200, Wipro GE, Bangalore, India)

DOI: $10.4103 / 0971-3026.54876$ revealed a single live fetus in cephalic presentation at 28 weeks of gestation. Important findings included severe polyhydramnios (amniotic fluid index: 34) [Figure 1], a highly echogenic aortic wall [Figure 2], echogenic cardiac outflow tracts [Figure 3], pericardial effusion, a large atrial septal defect, giving the appearance of a single atrium, bilateral pleural effusion, ascites, subcutaneous edema and echogenic kidneys. The rest of the organs appeared normal. Early grade III maturity of the placenta was noted. On the basis of the gray-scale findings, a diagnosis of IAC was made and fetal echo and follow-up scan were suggested. Followup scan after 1 week showed intrauterine fetal demise.

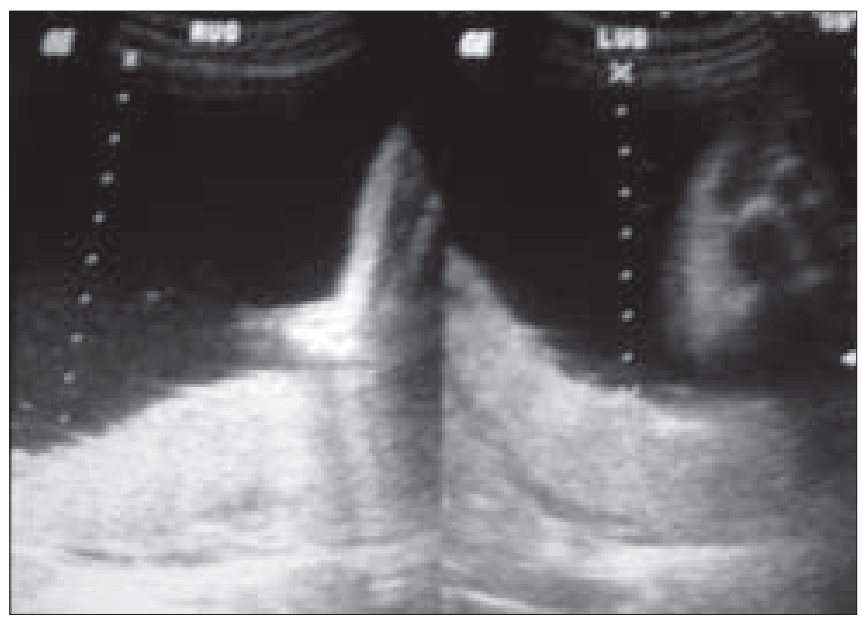

Figure 1: Abdominal USG of the uterus of the pregnant woman shows increased amniotic fluid (cursor) 
The dead fetus was delivered vaginally. Radiographic examination confirmed aortic calcification [Figure 4]. Autopsy of the fetus confirmed the other findings such as fetal hydrops, thickened cord-like aorta [Figure $5 \mathrm{~A}, \mathrm{~B}$ ] and large atrial septal defect. Histopathological examination showed calcification of the tunica intima and media. Sections from the kidneys, spleen, liver and thymus showed calcific deposits and parenchymal psammoma bodies.

\section{Discussion}

Idiopathic arterial calcification was first reported in 1901 by Bryant and White. ${ }^{[8]}$ Until now, 162 cases have been reported. The exact etiology of IAC is not known. An autosomal recessive inheritance pattern has been described. Recently, a genetic etiology was postulated: a homozygous

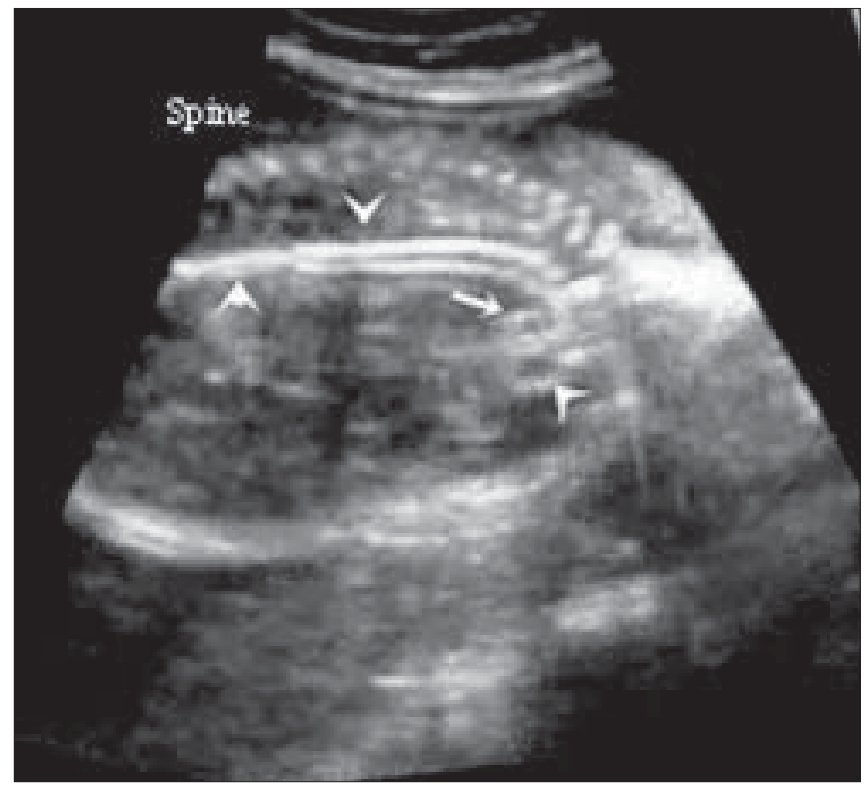

Figure 2: Sagittal USG of the fetal chest shows an echogenic aorta (arrowhead). The pulmonary artery is well seen (small arrow)

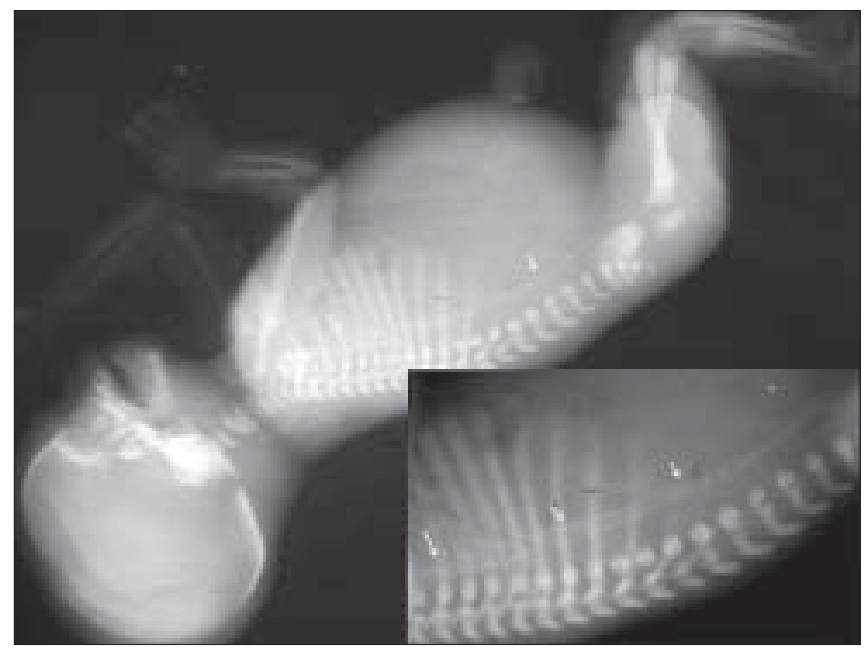

Figure 4: Lateral infantogram radiograph shows calcification of the aorta and iliac vessels (arrows) or compound heterozygous nonsense mutation for the ecto-nucleotide pyrophosphatase/phosphodiesterase 1 (ENPP1) gene on chromosome 6q. ${ }^{\left[{ }^{9]}\right.}$ The ENPP1 gene regulates extracellular inorganic pyrophosphate (PPi) level,

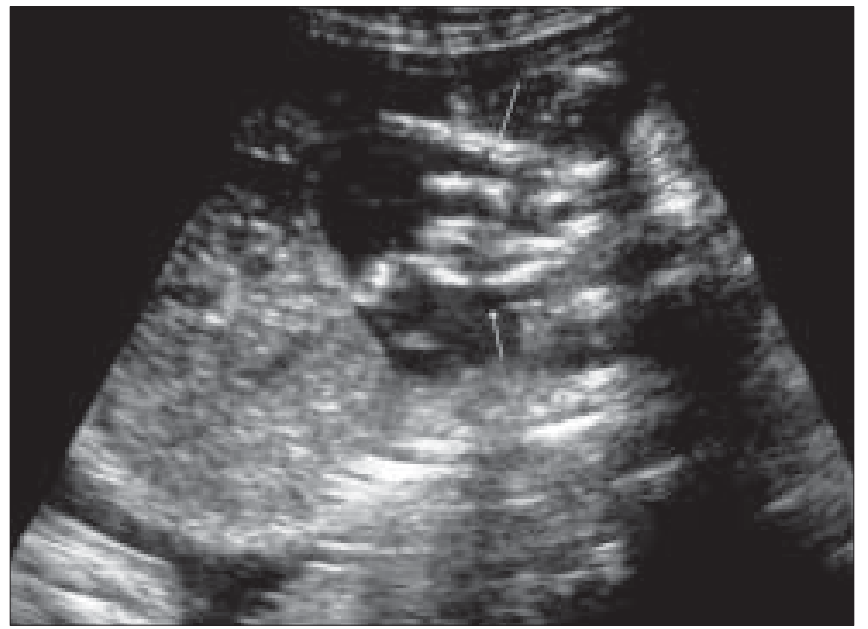

Figure 3: Oblique USG through the fetal chest shows echogenic outflow tracts (arrows)



Figure 5 (A, B): Gross specimen shows a thick, cord-like aorta (arrows) in profile $(A)$ and en face $(B)$ 
Table 1: Reported antenatal ultrasound findings in idiopathic arterial calcification

\begin{tabular}{|c|c|c|c|c|c|c|}
\hline \multirow{2}{*}{$\begin{array}{l}\text { No. of } \\
\text { cases }\end{array}$} & \multirow[t]{2}{*}{ Report and year } & \multirow{2}{*}{$\begin{array}{c}\text { Gestational age in } \\
\text { weeks }\end{array}$} & \multicolumn{4}{|c|}{ Sonographic findings } \\
\hline & & & Polyhydramnios & Echogenic aorta & Pericardial effusion & Hydrops fetalis \\
\hline 1 & Rosenbaum et al. $1986^{[2]}$ & 32 & NM & $P$ & NM & $P$ \\
\hline 2 & Stuart et al. 1990 & 33 & NM & $P$ & $P$ & NM \\
\hline \multirow[t]{2}{*}{3 and 4} & Spear et al. $1990^{[14]}$ & Twin I 32 & $P$ & $P$ & NM & $\mathrm{P}$ \\
\hline & & Twin II 31.5 & NM & $P$ & $\mathrm{P}$ & $P$ \\
\hline 5 & Samon et al. $1995^{[15]}$ & 28 & $P$ & $P$ & $\mathrm{P}$ & NM \\
\hline \multirow[t]{2}{*}{6 and 7} & Eronen et al. $2001^{[3]}$ & Twin I 29 & $P$ & NM & $P$ & $P$ \\
\hline & & Twin II 30 & $P$ & $P$ & $P$ & $\mathrm{P}$ \\
\hline 8 & Levine et al. $2001^{[16]}$ & 32 & $P$ & $P$ & $P$ & NM \\
\hline 9 & Nagaret et al. $2003^{[6]}$ & 27 & $P$ & $P$ & $P$ & $P$ \\
\hline 10 & Ciana et al. $2006^{[17]}$ & 26 & NM & $P$ & NM & NM \\
\hline
\end{tabular}

$\mathrm{P}$ - Present in the reported case, NM - Not mentioned in the reported case

and PPi regulates the matrix calcification. Thus, the ENPP1 mutation results in extracellular matrix calcification. ${ }^{[10]}$ Histologically, this is evident as intimal fibrous proliferation and calcium hydroxyapatite deposition in the intimal elastic lamina of the arteries. ${ }^{[4,11]}$ Extensive arterial calcification results in refractory hypertension and cardiac failure, and involvement of the coronary arteries causes myocardial ischemia. ${ }^{[3,45]}$ In the antenatal period, IAC presents with polyhydramnios, fetal hydrops or still birth. Most cases are diagnosed in infancy and, therefore, in some published reviews the condition is referred to as idiopathic arterial calcification (IAC) of infancy. ${ }^{[2]}$ Due to its rarity, the varied clinical presentation, and the rapid clinical worsening, most cases are diagnosed only at autopsy. ${ }^{[4,12]}$ Very few cases have been diagnosed antenatally on the basis of USG findings.

Common findings described on antenatal USG include echogenic aorta and outflow tracts, polyhydramnios, pericardial effusion and hydrops. Of these, echogenic aorta and outflow tracts are consistently seen [Table 1]. Our case showed all the above findings and, in addition, there were pleural effusions, ascites, edematous skin/subcutaneous tissue and a large atrial septal defect. All antenatally detected cases in the literature have been reported in the late second and third_trimesters, with the earliest detected case being at 26 weeks; our case was detected at 28 weeks of gestation [Table 1].

In this case, the parents were consanguineously married; the first child was normal and the second child had died during the early neonatal period. This history supports a genetic etiology. Confirmation of the USG findings was done by radiographic and postmortem examination.

Antenatal diagnosis of IAC can be made in the presence of an echogenic aorta, echogenic outflow tracts, polyhydramnios, pericardial effusion and fetal hydrops. A family history of IAC or polyhydramnios, with a previous perinatal death, should prompt antenatal screening for IAC; early detection of cases helps in counseling of the parents. An echocardiogram and genetic screening for ENPP1 mutation may be indicated in suspected cases. ${ }^{[4]}$

Until recently, IAC was considered a fatal condition. However, in a recent report, postnatal therapy with nitrogencontaining bisphosphonates such as low-dose disodium pamidronate, has shown rapid resolution of the arterial calcifications and better survival of the affected patients. ${ }^{[18]}$

\section{Acknowledgments}

Prof. H. Satishchandra, Prof. G Gurushanakar, Prof R K Saroja, Radiology postgraduates, BMCRI and the Department of Pathology BMCRI.

\section{References}

1. Bird T. Idiopathic arterial calcification in infancy. Arch Dis Child 1974;49:82-9.

2. Rosenbaum DM, Blumhagen JD. Sonographic recognition of idiopathic arterial calcification of infancy. AJR Am J Roentgenol 1986;146:249-50.

3. Eronen M, Pohjavuori M, Heikkila P. Fatal outcome of 2 siblings with idiopathic arterial calcification of infancy diagnosed in utero. Pediatr Cardiol 2001;22:167-9.

4. Glatz AC, Pawel BR, Hsu DT, Weinberg P, Chrisant MR. Idiopathic infantile arterial calcification: Two case reports, a review of the literature and a role for cardiac transplantation. Pediatr Transplant 2006;10:225-33.

5. Chong C, Hutchins G. Idiopathic Infantile Arterial Calcification: The Spectrum of Clinical Presentations. Pediatr Dev Pathol 2007 Aug 23:1.

6. Nagar AM, Hanchate V, Tandon A, Thakkar H, Chaubal NG. Antenatal Detection of Idiopathic Arterial Calcification With Hydrops Fetalis. J Ultrasound Med 2003;22:653-9.

7. Bellah RD, Zawodniak L, Librizzi RJ, Harris MC. Idiopathic arterial calcification of infancy: prenatal and postnatal effects of therapy in an infant. J Pediatr 1992;121:930-3.

8. Bryant JH, White WA. A case of calcification of the arteries and obliterative endarteritis associated with hydronephrosis in a child aged 6 months. Guys Hosp Rep 1901;55:17-28.

9. Rutsch F, Ruf N, Vaingankar S, Toliat MR, Suk A, Höhne W, et al. Mutations in ENPP1 are associated with 'idiopathic' infantile 
arterial calcification: Nat Genet 2003;34:379-81.

10. Numakura C, Yamada M, Ariyasu D, Maesaka A, Kobayashi H, Nishimura G, et al. Genetic and enzymatic analysis for two Japanese patients with idiopathic infantile arterial calcification. J Bone Miner Metab 2006;24:48-52.

11. Pashankar D, Moore L. Test and teach. Number eighty three: Part 1. Idiopathic arterial calcification of infancy. Pathology 1997;29:175,217.

12. Saigal G, Azouz EM The spectrum of radiologic findings in idiopathic arterial calcification of infancy: pictorial essay. Can Assoc Radiol J 2004;55:102-7

13. Stuart G, Wren C, Bain H. Idiopathic infantile arterial calcification in two siblings: failure of treatment with diphosphonate. Br Heart J 1990;64:156-9.

14. Spear R, Mack LA, Benedetti TJ, Cole RE. Idiopathic infantile arterial calcification: in utero diagnosis. J Ultrasound Med 1990;9:473-6
15. Samon LM, Ash KM, Murdison KA. Aorto-pulmonary calcification: an unusual manifestation of idiopathic calcification of infancy evident antenatally. Obstet Gynecol 1995;85:863-5.

16. Levine JC, Campbell J, Nadel A. Prenatal diagnosis of idiopathic infantile arterial calcification. Circulation 2001;103:325-6.

17. Ciana G, Trappan A, Bembi B, Benettoni A, Maso G, Zennaro F, et al. Generalized arterial calcification of infancy: Two siblings with prolonged survival. Eur J Pediatr 2006;165:258-63.

18. Ramjan KA, Roscioli T, Rutsch F, Sillence D, Munns CF. Generalized arterial calcification of infancy: Treatment with bisphosphonates. Nat Clin Pract Endocrinol Metab 2009;5:167-72.

Source of Support: Nil, Conflict of Interest: None declared. 